\title{
A cascade organic Rankine cycle power generation system using hybrid solar energy and liquefied natural gas
}

\author{
Pengcheng Li, Jing Li*, Gang Pei*, Jie Ji \\ Department of Thermal Science and Energy Engineering,
}

University of Science and Technology of China, Jinzhai Road 96, Hefei City,

Anhui Province, People's Republic of China

\begin{abstract}
A cascade organic Rankine cycle (ORC) system utilizing solar energy and liquefied natural gas (LNG) for thermal power generation is proposed. Energy from solar collectors drives the evaporation of working fluid in the top cycle (I). The heat released by cycle I facilitates the evaporation of working fluid in the bottom cycle (II). LNG is the cold source of cycle II. The system is optimized with respect to a new index, i.e., the equivalent efficiency, which denotes the ratio of the extra electricity produced by adding collectors and the received solar irradiation. Its advantages are clarified in comparison with existing indices like thermal efficiency, cold energy efficiency, and exergetic efficiency. The effects of working fluids on the system performance are investigated. Flat plate collectors (FPC) and evacuated tube collectors (ETC) are exemplified. It is shown that the equivalent efficiency is the most suitable index to embody the effectiveness of combination of solar collectors and LNG. A maximum equivalent efficiency of 5.99\% can be obtained on the use of isopentane/R125 and ETC. The volume ratio for each expander in the cascade ORC is much smaller than that in single-stage ORC, thereby resulting in easier design and manufacture of the expanders.
\end{abstract}


Keywords: organic Rankine cycle; LNG; solar energy; equivalent efficiency

*Corresponding authors. Tel./Fax: +86 551 63607367. E-mail: peigang@ustc.edu.cn, lijing83@ustc.edu.cn

\section{Introduction}

A large number of studies have focused on organic Rankine cycle (ORC) because it can realize low power turbomachinery more easily and react well to huge environment temperature fluctuations as compared with steam Rankine cycle. The low boiling points of organic fluids enable efficient conversion of low-grade heat such as industrial waste heat, geothermal heat, biomass and solar energy into power. The feasibility and superiority of ORC in electricity generation are outlined through both experimental studies (Pei et al. 2011, Li et al. 2012, Wang et al. 2010) and simulation works (Quoilin et al. 2010, 2011, Wang et al. 2013). Meanwhile, the cryogenic exergy of liquefied natural gas (LNG) pioneers new realm for ORC application.

LNG has attracted widespread attention owing to its cleanliness, nontoxicity, and low-cost. Its annual consumption is growing at $10 \%$ worldwide and the demand quantity will reach 500 million tons by 2030 according to the forecast by ExxonMobil (2008), the world's largest oil and gas producer. In general, LNG is stored within the storage tank at $111.51 \mathrm{~K}$ and $0.1 \mathrm{MPa}$ (Rao et al. 2013). The tank capacity is normally more than $10000 \mathrm{~m}^{3}$. The volume of natural gas (NG) can be reduced by 625 times by liquefying to facilitate marine or highway transportation. It's safer and more economic than pipeline transmission. 
More than $800 \mathrm{~kJ} / \mathrm{kg}$ cryogenic exergy can be released when LNG is vaporized to ambient temperature (Gu et al. 2004). The combinations of LNG regasification with refuse incineration, Brayton cycle, low-temperature waste heat recovery and supercritical $\mathrm{CO}_{2}$ Rankine-like cycle have been proposed (Miyazaki et al. 2000, Angelino et al. 2009, Shi et al. 2009, Song et al. 2012). More than 200 LNG satellite gasification stations have been established in China. An estimated $7.8 \times 10^{8} \mathrm{kWh}$ of electricity can be generated each year, equivalently saving $30 \times 10^{4}$ tons of standard coal (Xu et al. 2009). The most common way to utilize LNG for power generation is cryogenic ORC with seawater as heat source. Fifteen power plants of this type have been established in Japan with installed capacity of thousands of kilowatts.

Solar energy is an abundant and renewable resource, and combining it with LNG will be a desirable application prospect. Rao et al. (2013) has presented a hybridization of solar ORC and LNG. An analysis indicates that hybrid system has appreciable advantages in decreasing aperture area and heat exchanger costs as compared with separate solar ORC and LNG regasification systems.

In most cases, single-stage is adopted for the heat-to-power conversion of LNG. Due to the significant temperature difference $(>200 \mathrm{~K})$ between the hot and cold sides, the volume ratio (VR) of working fluid in single-stage ORC will be very high, and the expander will be complicated and expensive. To overcome these drawbacks, cascade ORC is an alternative choice (Xue et al. 2015). It is also more efficient than single-stage ORC.

In this paper, a hybrid solar/LNG power generation system based on cascade 
ORC is proposed. To the best knowledge of the authors, it's the first of this sort of system. Notably, there is a great challenge in the performance assessment of this novel system. Many existing indices might be taken as reference, such as thermal efficiency, cold energy efficiency, exergetic efficiency and cost per net power output (CPP).

Thermal efficiency is a good index to evaluate the performance of conventional solar ORC system (Pei et al. 2011; Quoilin et al. 2011). It indicates how effectively the absorbed solar energy is converted into electricity. Since the heat sink (air or water) is widely available and almost free, higher thermal efficiency is expected to offer shorter payback period for a constructed system. However, in the proposed system, the heat sink is LNG, which is valuable source. In terms of thermal efficiency, the contribution by cryogenic exergy of LNG is neglected. Higher thermal efficiency may require more LNG consumption, and thus the usage of LNG may be inefficient.

Cold energy efficiency is used to assess the extent of cryogenic exergy utilization for LNG regasification system (Liu et al. 2011; Deng et al. 2004), which denotes the ratio of electricity to the utilized cryogenic exergy of LNG. Higher cold energy efficiency means more power output at given amount of LNG, which is preferable because the heat source of solo LNG-ORC system is budget. But when the heat source is solar energy, higher cold energy efficiency may lead to larger aperture area of collectors and thus more initial investment.

Exergetic efficiency is able to indicate the irreversibility in the elements of 
thermodynamic system. It reflects the thermodynamic perfection of system. Nevertheless, it has no link with the cost-effectiveness. Higher exergetic efficiency may be accompanied with insufficient power conversion of LNG and solar energy, and more heat exchanger area.

Besides, CPP is frequently used as an optimum objective function, which is the ratio of total cost to the work output (Xue et al. 2015). But the cost of LNG is not covered in it. Comparison can be made between a system with high CPP and low LNG consumption per kilowatt, and a system with low CPP but high LNG consumption per kilowatt. Through long term operation, the profit by electricity generation of both systems will eventually offset the initial investment. Thereafter, the former will provide more power output at given amount of LNG, though it has a higher CPP. It manifests CPP is also a one-sided optimization criterion.

In summary, it is necessary to establish new index for the hybrid solar/LNG system. Equivalent efficiency, which denotes the ratio of the extra electricity produced by adding collectors and the received solar irradiation, is proposed in this paper. Its mathematical form is deduced in Section 3. System optimization is conducted with the objective function of equivalent efficiency. The influences of working fluids and collectors on the equivalent efficiency are investigated.

\section{System description and assumptions}

The schematic diagram of the cascade system is shown in Fig.1. The leftmost part is intermediate heat transfer cycle with a heat storage tank at the outlet of solar collector array. Compared with direct vapor generation of organic fluid, the pressure 
of collectors is much lower with water as heat transfer fluid. Moreover, stable power output can be realized and the risk of working fluid leakage is greatly reduced.

In the operation of cycle I, the heat gathered from solar collectors is carried away by water and transmitted to the fluid of cycle I (in red line) in heat exchanger 1 (HX1). High-pressure vapor enters into expander 1 (E1) and the mechanical work caused by the expansion process is recovered by E1. Subsequently, the heat released by the condensation of cycle I fluid is absorbed by the fluid of cycle II (in blue line) in HX2. The process of cycle II is similar to that of cycle I, except that the cryogenic exergy released by LNG evaporation is utilized to condense the cycle II fluid in HX3.

The rightmost part is the $\mathrm{LNG}$ regasification device. $\mathrm{LNG}$ at $111.51 \mathrm{~K}$ is withdrawn from the storage tank and pumped into HX3 to condense the cycle II fluid. Then LNG is gasified as saturated NG, which is still at cryogenic state. HX4 is added to superheat the gas to reach an appropriate temperature (approximately $10 \mathrm{~K}$ lower than ambient temperature). In this way, larger enthalpy drop can be realized and more electricity can be generated when superheated NG enters into E3. The exhaust stream can be further heated and conveyed to the city gas transmission and distribution network. The cooled air at the outlet of HX4 can be utilized as well, which is not discussed in this paper. The $T-S$ diagram of the corresponding state points is illustrated in Fig. 2.

The assumptions for the simulation are as follows:

(1) Working fluids are at saturated vapor state at the expander inlets except E3, and 
at saturated liquid state at the pump inlets. Solar collectors are working in steady state and have relatively uniform temperature distribution.

(2) Pinch-point temperature difference is $5 \mathrm{~K}$, and the pressure drop in each heat exchanger is $0.01 \mathrm{MPa}$. The other fixed parameters for calculation are shown in Table 1.

(3) LNG is assumed to be pure methane. It is saturated liquid under ambient pressure in the storage tank, and the evaporation pressure is $3 \mathrm{MPa}$. The outlet pressure of E3 is assumed to be $0.4 \mathrm{MPa}$. According to the given parameters and conditions, each state point for LNG is definite, as shown in Table 2.

\section{Mathematical model}

\subsection{Solar collectors}

The models of heat-collecting efficiency come from Solartechnik PrUfung Forchung (2010). Prototypes 1485 (ERA-Sun Es-24) for flat plate collectors (FPC) and 1647 (Zewotherm ZEWO-SOL ZX 30) for evacuated tube collectors (ETC) are exemplified. They are described by Eqs. (1)- (2):

$$
\begin{aligned}
& \eta_{P T C}=0.793-3.66 \times \frac{T_{m}-T_{0}}{G}-0.0098 \times \frac{\left(T_{m}-T_{0}\right)^{2}}{G} \\
& \eta_{E T C}=0.721-0.89 \times \frac{T_{m}-T_{0}}{G}-0.0199 \times \frac{\left(T_{m}-T_{0}\right)^{2}}{G}
\end{aligned}
$$

\subsection{Expanders}

The work generated by E1 is defined by Eq. (3):

$$
W_{E 1}=m_{\mathrm{I}}\left(h_{1}-h_{2}\right)=m_{\mathrm{I}} \eta_{E}\left(h_{1}-h_{2 s}\right)
$$

Similarly, for E2 and E3, 


$$
\begin{gathered}
W_{E 2}=m_{\mathrm{II}}\left(h_{5}-h_{6}\right)=m_{\mathrm{II}} \eta_{E}\left(h_{5}-h_{6 s}\right) \\
W_{E 3}=m_{L N G}\left(h_{12}-h_{13}\right)=m_{L N G} \eta_{E}\left(h_{12}-h_{13 s}\right)
\end{gathered}
$$

VR for each expander is defined as Eq. (6):

$$
V R=\frac{v_{\text {out }}}{v_{\text {in }}}
$$

\subsection{Heat exchangers}

Calculation starts with the cold side, and $m_{L N G}$ is assumed to be $1 \mathrm{~kg} / \mathrm{s}$, then $m_{\mathrm{I}}$ and $m_{\mathrm{II}}$ can be calculated based on heat balance Eqs. (7)- (9):

$$
\begin{gathered}
m_{L N G}\left(h_{11}-h_{10}\right)=m_{\mathrm{II}}\left(h_{6}-h_{7}\right) \\
m_{\mathrm{II}}\left(h_{5}-h_{8}\right)=m_{\mathrm{I}}\left(h_{2}-h_{3}\right) \\
C_{w} m_{w}\left(T_{15}-T_{14}\right)=m_{\mathrm{I}}\left(h_{1}-h_{4}\right)
\end{gathered}
$$

\subsection{Pumps}

The required work by P1 is given by Eq. (10) (Basic theory centrifugal pumps, 2013).

$$
W_{p 1}=\frac{m_{w} H}{102 \eta_{p}}
$$

For organic fluid pumps (P2, P3, P4),

$$
\begin{gathered}
W_{p 2}=m_{\mathrm{I}}\left(h_{4}-h_{3}\right)=\frac{m_{\mathrm{I}}}{\eta_{p}}\left(h_{4 s}-h_{3}\right) \\
W_{p 3}=m_{\mathrm{II}}\left(h_{8}-h_{7}\right)=\frac{m_{\mathrm{II}}}{\eta_{p}}\left(h_{8 s}-h_{7}\right) \\
W_{p 4}=m_{L N G}\left(h_{10}-h_{9}\right)=\frac{m_{L N G}}{\eta_{p}}\left(h_{10 s}-h_{9}\right)
\end{gathered}
$$

The parameter of each state point for LNG is definite and obtained as $\mathrm{T}_{7}=$ 182.27 $\mathrm{K}$ by the relationship of pinch-point temperature difference. Similarly, $\mathrm{T}_{5}$ can 
be determined if $T_{3}$ is given. In this way, all the temperature points of the system can be simplified into two variables, defined as a two-dimensional vector $\left(\mathrm{T}_{1}, \mathrm{~T}_{3}\right)$, and calculation can be remarkably simplified.

3.5. Thermal efficiency

$$
\eta_{T}=\eta_{O R C} \cdot \eta_{P T C / E T C}=\frac{W_{n e t}}{G \cdot A}
$$

where

$$
\begin{gathered}
\eta_{O R C}=\frac{W_{n e t}}{m_{\mathrm{I}}\left(h_{1}-h_{4}\right)} \\
W_{n e t}=\left(W_{E 1}+W_{E 2}+W_{E 3}\right) \cdot \varepsilon_{g}-\left(W_{P 1}+W_{P 2}+W_{P 3}+W_{P 4}\right)
\end{gathered}
$$

3.6. Cold energy efficiency

$$
\eta_{C}=\frac{W_{n e t}}{E_{L N G}}
$$

where $E_{L N G}$ is the maximum available cryogenic exergy of $1 \mathrm{~kg} / \mathrm{s} \mathrm{LNG.}$

$$
E_{L N G}=\left(h_{9}-T_{0} S_{9}\right)-\left(h_{13}-T_{0} S_{13}\right)
$$

\subsection{Exergetic efficiency}

The maximum available exergy released by solar radiation is defined as Eq. (19).

(Winter et al. 1991)

$$
E_{S}=G A\left[1-\frac{4 T_{0}}{3 T_{S}}(1-0.28 \ln f)\right]
$$

where $f$ is the dilution factor, $f=1.3 \times 10^{-5}$.

Exergy exists in solar energy and LNG, both collectors and LNG require a certain cost. Therefore, they should be considered simultaneously when calculating exergetic efficiency. 


$$
\eta_{e x}=\frac{W_{n e t}}{E_{S}+E_{L N G}}
$$

\subsection{Equivalent efficiency}

For the hybrid solar/LNG power generation system, both heat source and heat sink are estimable. The equivalent efficiency proposed in the work contains comprehensive information on the heat source and heat sink. In particular, it is a relative index and emphasizes the collectors' contribution to the system power generation. There are two reasons. First, technical and economic feasibility of LNG-ORC system with seawater as heat source have been well demonstrated by existing LNG power plants. Investigation on such system has been carried out intensively. Performance of solo LNG-system can be the reference for other LNG-related systems. Second, knowledge about the combination of solar energy and LNG is rare. It is interesting to know whether the hybrid solar/LNG ORC system is more advantageous or not as compared to LNG-ORC system. A close view of the relative efficiency increment of the hybrid system over the LNG-ORC system will be beneficial.

The power contribution of the collectors can be determined by subtracting the power generated by LNG. The equivalent efficiency is therefore expressed by

$$
\eta_{e q}=\frac{W_{n e t}-W_{\max }}{G A}
$$

$W_{\max }$ is the power contributed by LNG. It is calculated by the following ways. A system without solar collectors is supposed. This system is similar with the hybrid solar/LNG system, except that the water in HX1 in Fig.1 is replaced by seawater. 
The temperature of seawater is assumed to be equal to the ambient temperature. The mass flow rate of LNG, working fluid, expander and pump efficiencies, pinch point temperature etc. are the same as those in the hybrid system. $W_{\max }$ is maximum power output of the supposed system through optimization of $\mathrm{T}_{1}$ and $\mathrm{T}_{3}$.

Hence, $\left(W_{n e t}-W_{\max }\right)$ is equivalent to the extra electricity that is produced by adding the collectors. $\eta_{e q}$ denotes the ratio of the extra electricity and the received solar irradiation. It is strongly correlated with the effectiveness of combination of solar collectors and LNG. A higher $\eta_{e q}$ means more power output at given aperture area and a shorter payback period in regard to the investment of solar collectors.

\section{Results and discussion}

Detailed analysis is conducted based on the mathematical models and different indices. Influences of working fluids and collectors on system performance are conducted as well.

Working fluid is a key issue in ORC system. Following thermodynamic properties are taken into account: the critical temperature is higher than the maximum operating temperature; the condensing pressure is above $5 \mathrm{kPa}$ as it is technically difficult to maintain a vacuum below this value in the condenser (Fernández. et al. 2011; Drescher. et al. 2007); the triple-point temperature is maintained below the minimum operating temperature. Ammonia, R227ea, RC318 and isopentane perform well in low temperature source and cascade ORC systems (Tchanche. et al. 2009, Xue et al. 2015, Desai et al. 2009); Ethane, R116 and R125 have suitable condensing pressures in very low temperature range (Cayer. et al. 2010, 
Xue et al. 2015). Their thermodynamic properties are shown in Table 3.

\subsection{Comparison among different indices}

To compare different indices for the hybrid system, ammonia and ethane are exemplified in cycles I and II, respectively. FPC is adopted as heat collection unit.

\subsubsection{Thermal efficiency}

Fig. 3 illustrates the variation of thermal efficiency with respect to $T_{1}$ and $T_{3}$. With the increment in $T_{3}$ at certain evaporation temperature $\left(T_{1}\right)$, thermal efficiency remains relatively stable. The red dashed line intersecting with the efficiency curves denotes the maxima, which are achieved at $\mathrm{T}_{3}$ of $235 \sim 250 \mathrm{~K}$. However, thermal efficiency shows a downward trend as evaporation temperature increases at given $\mathrm{T}_{3}$. Furthermore, the interval between neighboring curves gets larger from the upper portion of the figure to the bottom, which indicates that higher evaporation temperature results in more obvious decline in thermal efficiency. Thermal efficiency decreases monotonously with the increment in evaporation temperature. This phenomenon is contrary to that of conventional solar ORC, in which thermal efficiency first increases and then decreases as the evaporation temperature rises (Quoilin et al. 2011; Li et al. 2012). The reason is that in the hybrid system, heat-to-power conversion efficiency $\left(\eta_{O R C}\right)$ increases marginally, whereas the heat collection efficiency $\left(\eta_{F P C}\right)$ decreases significantly with the increment in evaporation temperature. For example, $\eta_{\text {ORC }}$ increases from $44.79 \%$ to $48.76 \%$ when $\left(\mathrm{T}_{1}, \mathrm{~T}_{3}\right)$ varies from $(303 \mathrm{~K}, 245 \mathrm{~K})$ to $(363 \mathrm{~K}, 245 \mathrm{~K})$, whereas $\eta_{F P C}$ decreases from $74.71 \%$ to $47.70 \%$. According to the formula (14), the product of the 
two still undergoes reduction.

The maximum thermal efficiency occurs when the heat source temperature approaches the ambient temperature. The solar collectors become redundant. From this viewpoint, thermal efficiency is not an appropriate index for the performance assessment of the hybrid system, though it is widely used in conventional solar thermal power system.

\subsubsection{Cold energy efficiency}

Fig. 4 illustrates the cold energy efficiency varying with $\mathrm{T}_{1}$ and $\mathrm{T}_{3}$. The variation of cold energy efficiency at certain $T_{1}$ with the increase in $T_{3}$ is more appreciable as compared with that in Fig. 3. Given $\mathrm{T}_{1}, \mathrm{~T}_{3}$ at which the cold energy efficiency reaches the maximum is the same as that in Fig. 3, because in both cases the ORC efficiency is maximized. The cold energy efficiency increases as the evaporation temperature rises, and the extent of increment becomes smaller as $\mathrm{T}_{1}$ increases. Fig. 4 shows that the cryogenic exergy of LNG can be more sufficiently utilized if FPC is incorporated when the mass flow rate and state parameters of LNG are fixed, and the advantage is more distinct in the low-temperature segment of $\mathrm{T}_{1}$. It manifests that FPC can play an important role in exploiting the cryogenic exergy of LNG.

On the other hand, the cold energy efficiency increases monotonously with the increment in $\mathrm{T}_{1}$. Higher cold energy efficiency leads to higher temperature in the solar field and lower heat collection efficiency. To supply high grade heat source, the aperture area will be inevitably large and the cost will be huge. Therefore, the cold energy efficiency is not a favorable index for the hybrid solar/LNG system either. 


\subsubsection{Exergetic efficiency}

Fig. 5 shows exergetic efficiency varying with $\mathrm{T}_{1}$ and $\mathrm{T}_{3}$. Each $\mathrm{T}_{3}$ that corresponds to the peak exergetic efficiency at given $T_{1}$ is the same as those shown in Figs. 3 and 4. On constant condition of $\mathrm{T}_{3}$, the variation of exergetic efficiency is slight when $\mathrm{T}_{1}$ increases from $303 \mathrm{~K}$ to $323 \mathrm{~K}$, and then an apparent reduction appears when $\mathrm{T}_{1}$ is above $323 \mathrm{~K}$. Given the state points and mass flow rate of LNG, exergy losses in P4, HX3, HX4 and E3 are explicit. Higher evaporation temperature leads to larger temperature difference between $\mathrm{T}_{1}$ and $\mathrm{T}_{7}$ and thus more irreversible losses in the rest of the components. According to Eq. (20), exergetic efficiency involves information on the available energy of heat source and heat sink, and is influenced by the reference point. It indicates that a higher degree of thermodynamic perfection of the cascade system is reached at low evaporation temperature. However, the relative power contributions by solar energy and LNG are not clear. When the evaporation temperature is close to the ambient temperature, solar collectors is not sufficiently used though the exergetic efficiency can be optimum.

\subsubsection{Equivalent efficiency}

Fig. 6 illustrates equivalent efficiency varying with $T_{1}$ and $T_{3}$. Equivalent efficiency climbs as evaporation temperature rises, but the degree of increment is not distinct in the high-temperature segment. Particularly, the curves for evaporation temperatures of $353 \mathrm{~K}$ and $363 \mathrm{~K}$ are substantially overlapped. The peak equivalent efficiency at $363 \mathrm{~K}$ is about $4.69 \%$, which is slightly lower than that at $353 \mathrm{~K}$. The dashed red line shows that the peak equivalent efficiency is a function of $\mathrm{T}_{1}$, which 
increases first and then decreases with the increment in $\mathrm{T}_{1}$.

To compare the four indices, maxima of these efficiencies and the corresponding state points in the range of $\mathrm{T}_{1}$ from $303 \mathrm{~K}$ to $363 \mathrm{~K}$ are shown in Table $4 . \mathrm{T}_{6} / \mathrm{P}_{6}$ and $\mathrm{T}_{7} / \mathrm{P}_{7}$ are constant values of $182 \mathrm{~K} / 0.10 \mathrm{MPa}$ and $182 \mathrm{~K} / 0.09 \mathrm{MPa}$, respectively, and they are not exhibited.

Table 4 points out that optimum parameters in the hybrid system are quite different. Thermal efficiency is faulty as the effect of cold-power conversion of LNG is not considered. Cold energy efficiency is deficient as the increased FPC cost for purpose of raising the heat source temperature is excluded. Exergetic efficiency is imperfect due to the independence from cost-effectiveness. The equivalent efficiency, on the contrary, is a relative index, which reveals the impact of collectors on the system power output. Optimal equivalent efficiency denotes the largest amount of extra electricity contributed by solar energy, resulting in a quick return on the collector investment. It is the most suitable index to embody the effectiveness of combination of solar collectors and LNG.

\subsection{Influences of working fluids on the equivalent efficiency}

Figs. 7-12 show equivalent efficiencies varying with $\mathrm{T}_{1}$ and $\mathrm{T}_{3}$ on the use of R227ea/R116，R227ea/R125，RC318/R116，RC318/R125，isopentane/R116 and isopentane/R125. The fluids at the left and right sides of the oblique line are for cycles I and II, respectively. The curves exhibit parabolic growth and some are asymmetric as supercritical cycle is not considered. For each group of the working fluids, the equivalent efficiency is a function of $\mathrm{T}_{1}$ and $\mathrm{T}_{3}, \eta_{e q}=f_{13}\left(T_{1}, T_{3}\right)$. For every 
$\mathrm{T}_{1}$, there is a $\mathrm{T}_{3}$ at which a peak equivalent efficiency $\left(\eta_{e q, p}\right)$ is reached. $\eta_{e q, p}$ is a function of $\mathrm{T}_{1}, \eta_{e q, p}=f_{1}\left(T_{1}\right)$. The maximum values of $f_{13}\left(T_{1}, T_{3}\right)$ and $f_{1}\left(T_{1}\right)$ are same. The maxima and corresponding state points are listed in Table 5. The highest equivalent efficiency is achieved on the use of isopentane/R125, which is about $5.20 \%$. While in case of R227ea/R116, the maximum $\eta_{e q}$ is only $3.66 \%$. Depending on the fluids, $\mathrm{T}_{1}$ at the maximum $\eta_{e q}$ is generally in the interval of $353 \mathrm{~K} \sim 357 \mathrm{~K}$, and $\mathrm{T}_{3}$ ranges from $256 \mathrm{~K}$ to $277 \mathrm{~K}$. In addition, for the same fluid in cycle I, efficiency with R125 in cycle II is higher than that with R116. The results imply that the working fluids have appreciable influence on the equivalent efficiency.

4.3. Influences of solar collectors on the equivalent efficiency

Aside from FPC, ETC is one type of collectors widely used in low-medium temperature application. The equivalent efficiency curves in regard to $T_{3}$ for different fluids on the use of ETC have similar shape with those in Figs. 7-12, which open downward and have peak points. For simplicity, only peak equivalent efficiency for each curve is extracted in the case of ETC, and its variation with $\mathrm{T}_{1}$ is shown in Fig. 13. The peak efficiency increases almost monotonously with the increment in $\mathrm{T}_{1}$ in the temperature range below $363 \mathrm{~K}$. At given $\mathrm{T}_{1}$, isopentane/R125 offer higher efficiency than other working fluids.

The maxima of the peak equivalent efficiency for each group of fluids on the use of ETC and the corresponding state points are listed in Table 6. Similar with Table 5, the highest equivalent efficiency is achieved on the use of isopentane/R125, which is 
$5.99 \%$. While in case of R227ea/R116, the maximum $\eta_{e q}$ is only $4.14 \% . \mathrm{T}_{1}$ at the maximum $\eta_{e q}$ is generally in the interval of $360 \mathrm{~K} \sim 363 \mathrm{~K}$, and $\mathrm{T}_{3}$ ranges from $256 \mathrm{~K}$ to $280 \mathrm{~K}$. The results indicate the maximum $\eta_{e q}$ with ETC is higher than that with FPC for the same group of working fluids.

\subsection{Economic analysis}

ETC is taken as example. The cost of commercial ETC in China is about 500 $\mathrm{RMB} / \mathrm{m}^{2}$ (about 75 euro $/ \mathrm{m}^{2}$ ). In case of isopentane/R125, a maximum equivalent efficiency of $5.99 \%$ is achieved. The required aperture area is $16.70 \mathrm{~m}^{2} / \mathrm{kW}$ under the assumption that solar radiation is $1 \mathrm{~kW} / \mathrm{m}^{2}$. The cost for solar collectors is then about $8350 \mathrm{RMB} / \mathrm{kW}$. It is comparable with the current cost of a photovoltaic system without storage (8000 RMB/kW) and much lower than a photovoltaic system with 5 hour battery storage (30500 RMB/kW) (C. et al. 2014, Li. 2015). In view of the cheap storage of water, the payback period of the solar collectors will be much shorter than that of photovoltaic system with storage. Besides, the efficiency of $5.99 \%$ is even higher than conventional solar ORC systems using non-concentrated collectors (Manolakos et al. 2007, Wang et al. 2010). The solar collectors in the hybrid solar/LNG system can bring in significant power output, while share the ORC with LNG. Therefore, the hybrid system will be definitely more economically competitive than the stand alone solar ORC.

\subsection{Comparisons of VR for single-stage and cascade ORC systems}

The above sections have indicated that the hybrid power generation system is efficient. Technical advantage of the cascade ORC is discussed in this section. 
Three wet fluids: R143a, followed by propane and propene emerged as most suitable working fluids in single-stage ORC (Rao et al, 2013). Besides, dry fluid R125 has suited condensing pressure and critical temperature among all the fluids in Table 3. Fig.14 shows the VR of single-stage ORC varying with evaporation temperature on the use of these four fluids. The condensation temperature is 182.27K, which is same as $\mathrm{T}_{7}$ in Fig. 1.

Although superheat is necessary for the three wet fluids, VR varies very little. Take R143a as an example, the required minimum superheat is $310 \mathrm{~K}$ when evaporation temperature is $303 \mathrm{~K}$ and the corresponding VR is 67.4 . VR only drops to 64.7 when turbine inlet temperature increases to $363 \mathrm{~K}$. The decrement of VR is only 4\%. Therefore, Fig.14 can be approximately deemed as VR varying with turbine inlet temperature. It can be seen all the VRs are above 50 when evaporation temperature is higher than $300 \mathrm{~K}$.

Notably, efficiencies over $80 \%$ can be achieved for single-stage axial turbine only when the VR is below 50 (Invernizzi et al. 2007; Shu et al. 2014). Multi-stage expansion and a complicated turbine are inevitable in the above cases, which increase the dimension and cost of the equipment. In addition, high VR results in increment in the rotor exit Mach number of gas turbo expander. The high velocity of the flow exiting the rotor blade passage not only reduces the turbine efficiency and results in energy loss, but also causes shock wave or expansion wave inside the turbine (Li et al. 2013).

By contrast, VRs for E1 and E2 in the cascade system are far lower than 50 as 
shown in the last columns of Tables 5 and 6. VR for E3 is a fixed value of 5.3. Single-stage turbines will run efficiently because lower values of VR deliver higher turbine efficiency (Macchi. et al. 1981).

\section{Conclusions}

This study proposes a cascade ORC and an optimization criterion for the hybridization of solar energy and LNG for power generation. All of the temperatures of the system are simplified as a two-dimensional vector $\left(\mathrm{T}_{1}, \mathrm{~T}_{3}\right)$ for calculation. In-depth research and summary are conducted with regard to different evaluation indices. Finally, thermo-economic analysis is carried out using different working fluids and collectors. Following conclusions can be drawn from the results:

(1) For the system that utilizes solar energy and LNG, thermal efficiency and cold energy efficiency are deficient. Neither of them is suitable optimization criterion. Exergetic efficiency that is based on heat source and sink simultaneously can be utilized as a thermodynamic index to evaluate the overall performance. A higher degree of thermodynamic perfection is reached at low evaporation temperature.

(2) Equivalent efficiency is proposed to denote the ratio of the extra electricity that is caused by adding solar collectors and the received solar energy. The effectiveness of the hybridization of solar collectors and LNG is revealed by equivalent efficiency. The optimal values vary with different combinations of working fluids and the results obtained by ETC are higher than those by FPC under the selected models. Maximum $5.99 \%$ can be achieved by using 
isopentane/R125 and ETC. The corresponding electricity cost is 8350 $\mathrm{RMB} / \mathrm{kW}$ and comparable with the current cost of a photovoltaic system without storage.

(3) Compared with the single-stage ORC, the VR for each turbine in the cascade ORC is much smaller, thereby enabling easier design and manufacture of turbines. As a result, the technical difficulties and high cost associated with multistage expansion can be avoided.

\section{Acknowledgment}

This study was sponsored by the (1) National Science Foundation of China (NSFC 51178442, 51476159, 51206154) and the (2) Fundamental Research Funds for the Central Universities.

\section{REFERENCE}

Angelino, G., Invernizzi, C.M., 2009. Carbon dioxide power cycles using liquid natural gas as heat sink. Applied Thermal Engineering, 29, 2935-2941.

$\begin{array}{llll}\text { Basic theory } & \text { centrifugal }\end{array}$ <http://www.doc88.com/p-9495494729368.html>

C. Ma, 2014. The core competence of solar thermal power technology. In: China CSP investment and financing summit and CSPPLAZA 2014 annual conference, 
Beijing, 23-24 Aug 2014.

Cayer, E., Galanis, N., Nesreddine, H., 2010. Parametric study and optimization of a transcritical power cycle using a low temperature source. Applied Energy, 87, 13491357.

Deng, S.M., Jin, H.G., Cai, R.X., Lin, R.M., 2004. Novel cogeneration power system with liquefied natural gas (LNG) cryogenic exergy utilization. Energy, 29, 497512.

Desai, NB., Bandyopadhyay, S., 2009. Process integration of organic Rankine cycle. Energy, 34, 1674-1686.

Drescher, U., Brüggemann, D., 2007. Fluid selection for the organic Rankine cycle in biomass power and heat plants. Applied Thermal Engineering, 27, 223-228.

ExxonMobil, 2008. <http://chinacir.com.cn/ywzx/200854114210.shtml>

Fernández, F.J., Prieto, M.M., Suárez, I., 2011. Thermodynamic analysis of high-temperature regenerative organic Rankine cycles using siloxanes as working fluids. Energy, 36, $5239-5249$.

Gu, A.Z., 2004. Liquefied natural gas technology. Chapter 7 Page 266 (in Chinese).

Invernizzi, C., Iora, P., Silva, P., 2007. Bottoming micro-Rankine cycles for micro-gas turbines. Applied Thermal Engineering, 27, 100-110.

Li, J., 2015. Structural Optimization and Experimental Investigation of the Organic Rankine Cycle for Solar Thermal Power Generation. Springer Theses, Chapter 2, 41.

Li, J., Pei, G., Li Y.Z., Wang D.Y., Ji, J., 2012. Energetic and exergetic investigation 
of an organic Rankine cycle at different heat source temperatures. Energy, 38, 85-95.

Li, J., Pei, G., Li, Y.Z., Wang, D.Y., Ji, J., 2013. Examination of the expander leaving loss in variable organic Rankine cycle operation. Energy Conversion and Management, 65, 66-74.

Liu, Y.N., Guo, K.H., 2011. A novel cryogenic power cycle for LNG cold energy recovery. Energy, 36, 2828-2833.

Macchi, E., Perdichizzi, A., 1981. Efficiency prediction for axial-flow turbines operatin with non conventional fluids. Trans ASME, J Eng Power, 103, 718-24.

Manolakos, D., Papadakis, G., Kyritsis, S., Bouzianas, K., 2007. Experimental evaluation of an autonomous low-temperature solar Rankine cycle system for reverse osmosis desalination. Desalination, 203, 366-374.

Miyazaki, T., Kang, Y.T., Akisawa, A., Kashiwagi, T., 2000. A combined power cycle using refuse incineration and LNG cold energy. Energy, 25, 639-655.

Pei, G., Li, J., Ji, J., 2011. Design and analysis of a novel low-temperature solar thermal electric system with two-stage collectors and heat storage units. Renewable Energy, 36, 2324-2333.

Pei, G., Li, J., Li Y.Z., Wang, D.Y., Ji, J., 2011. Construction and dynamic test of a small-scale organic rankine cycle. Energy, 36, 3215-3223.

Quoilin, S., Lemort, V., Lebrun, J., 2010. Experimental study and modeling of an Organic Rankine Cycle using scroll expander. Applied Energy, 87, 1260-1268.

Quoilin, S., Orosz, M., Hemond, H., Lemort, V., 2011. Performance and design 
optimization of a low-cost solar organic Rankine cycle for remote power generation. Solar Energy, 85, 955-966.

Rao, W.J., Zhao, L.J., Liu, C., Zhang, M.J., 2013. A combined cycle utilizing LNG and low-temperature solar energy. Applied Thermal Engineering, 60, 51-60.

Shi, X.J., Che, D.F., 2009. A combined power cycle utilizing low-temperature waste heat and LNG cold energy. Energy Conversion and Management, 50, 567-575.

Shu, G.Q., Li, X.N., Tian, H., Liang, X.Y., Wei, H.Q., Wang, X., 2014. Alkanes as working fluids for high-temperature exhaust heat recovery of diesel engine using organic Rankine cycle. Applied Energy, 119, 204-217.

$\begin{array}{llll}\text { Solartechnik } & \text { PrUfung } & \text { Forchung, }\end{array}$ <http://www.solarenergy.ch/index.php?id=111\&L=6\&no_cache $=1>$

Song, Y.H., Wang, J.F., Dai, Y.P., Zhou, E.M., 2012. Thermodynamic analysis of a transcritical $\mathrm{CO}_{2}$ power cycle driven by solar energy with liquified natural gas as its heat sink. Applied Energy, 92, 194-203.

Tchanche, B.F., Papadakis, G., Lambrinos, G., Frangoudakis, A., 2009. Fluid selection for a low-temperature solar organic Rankine cycle. Applied Thermal Engineering, 29, 2468-2476.

Wang, M., Wang, J.F., Zhao, Y.Z., Zhao, P., Dai, Y.P., 2013. Thermodynamic analysis and optimization of a solar-driven regenerative organic Rankine cycle (ORC) based on flat-plate solar collectors. Applied Thermal Engineering, 50, 816-825.

Wang, X.D., Zhao, L., Wang, J.L., Zhang, W.Z., Zhao, X.Z., Wu, W., 2010. Performance evaluation of a low temperature solar Rankine cycle system 
utilizing R245fa. Solar Energy, 84, 353-364.

Winter, CJ., Sizmann, RL., Vant-Hull, LL., 1991. Solar power plants: fundamentals, technology, systems, economics. New York: Springer.

Xue, X.D., Guo, C., Du, X.Z., Yang, L.J., Yang, Y.P., 2015. Thermodynamic analysis and optimization of a two-stage organic Rankine cycle for liquefied natural gas cryogenic exergy recovery. Energy, 83, 778-787.

Xu, W.D., Bian, H.J., Fan, S.S., Hua, B., 2009. Cold energy utilization technology of LNG satellite gasification station. Natural Gas Industry, 29, 112-114.

Figure Legend

Fig. 1. Schematic diagram of the cascade system utilizing solar energy and LNG

Fig. 2. T-s diagram with the state points as defined in Fig. 1

Fig. 3. Thermal efficiency varying with $\mathrm{T}_{1}$ and $\mathrm{T}_{3}$

Fig. 4. Cold energy efficiency varying with $\mathrm{T}_{1}$ and $\mathrm{T}_{3}$

Fig. 5. Exergetic efficiency varying with $\mathrm{T}_{1}$ and $\mathrm{T}_{3}$

Fig. 6. Equivalent efficiency varying with $\mathrm{T}_{1}$ and $\mathrm{T}_{3}$

Fig. 7. Equivalent efficiency varying with $T_{1}$ and $T_{3}$ on the use of isopentane /R116

Fig. 8. Equivalent efficiency varying with $\mathrm{T}_{1}$ and $\mathrm{T}_{3}$ on the use of isopentane /R125

Fig. 9. Equivalent efficiency varying with $\mathrm{T}_{1}$ and $\mathrm{T}_{3}$ on the use of R227ea /R116 
Fig. 10. Equivalent efficiency varying with $\mathrm{T}_{1}$ and $\mathrm{T}_{3}$ on the use of R227ea /R125

Fig. 11. Equivalent efficiency varying with $\mathrm{T}_{1}$ and $\mathrm{T}_{3}$ on the use of RC318 /R116

Fig. 12. Equivalent efficiency varying with $\mathrm{T}_{1}$ and $\mathrm{T}_{3}$ on the use of $\mathrm{RC} 318$ /R125

Fig. 13. Peak equivalent efficiency at each $\mathrm{T}_{1}$ on the use of ETC

Fig. 14. VR of the single-stage ORC varying with evaporation temperature

Table legend

Table 1. Fixed parameters for calculation

Table 2. Parameters of each state point for LNG

Table 3. Thermodynamic properties of the working fluids

Table 4. Maxima of various efficiencies and corresponding state points for ammonia and ethane

Table 5. Maximum equivalent efficiencies for different fluids on the use of FPC

Table 6. Maximum equivalent efficiencies for different fluids on the use of ETC 


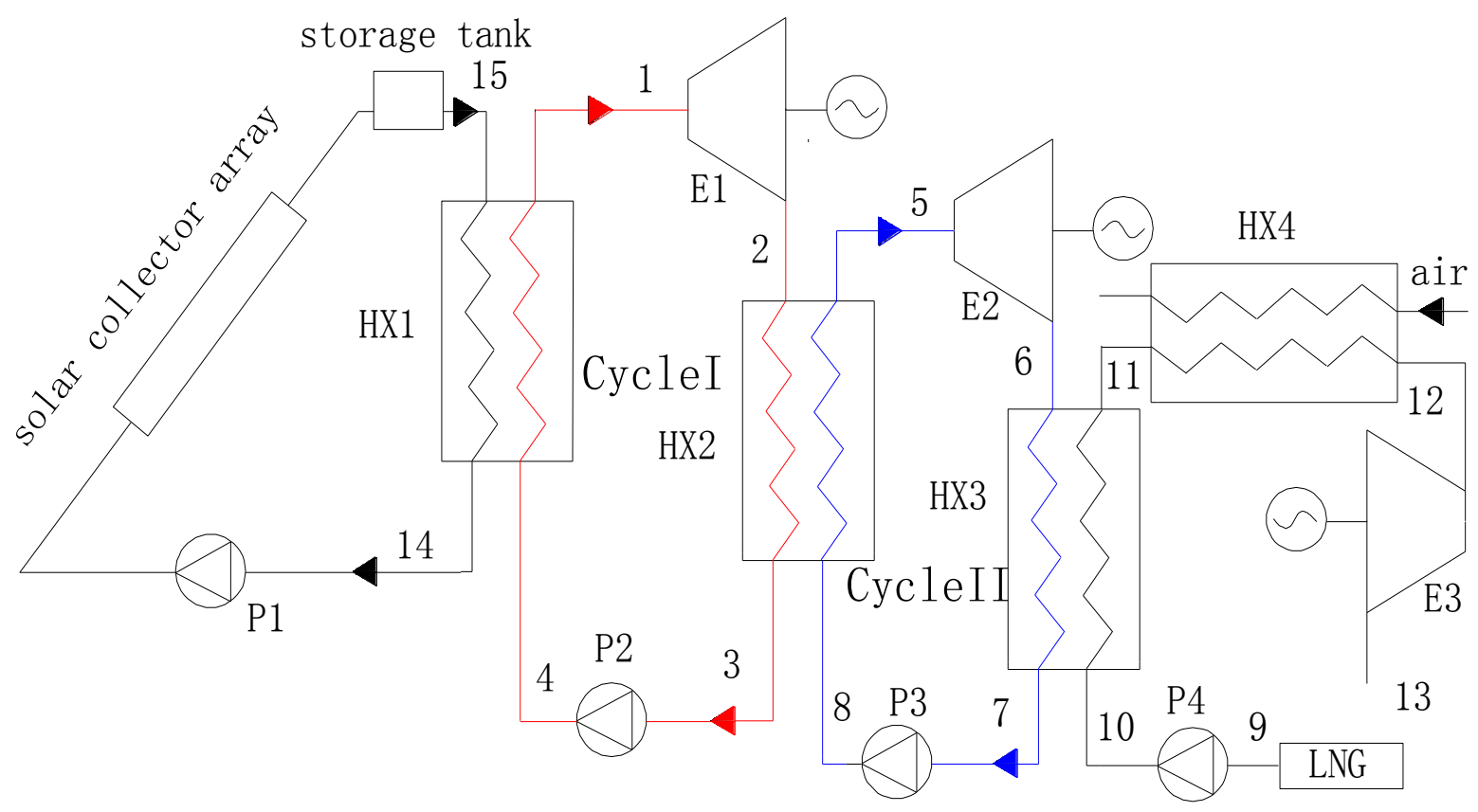

Fig. 1. Schematic diagram of the cascade system utilizing solar energy and LNG.

E: expander; HX: heat exchanger; P: pump

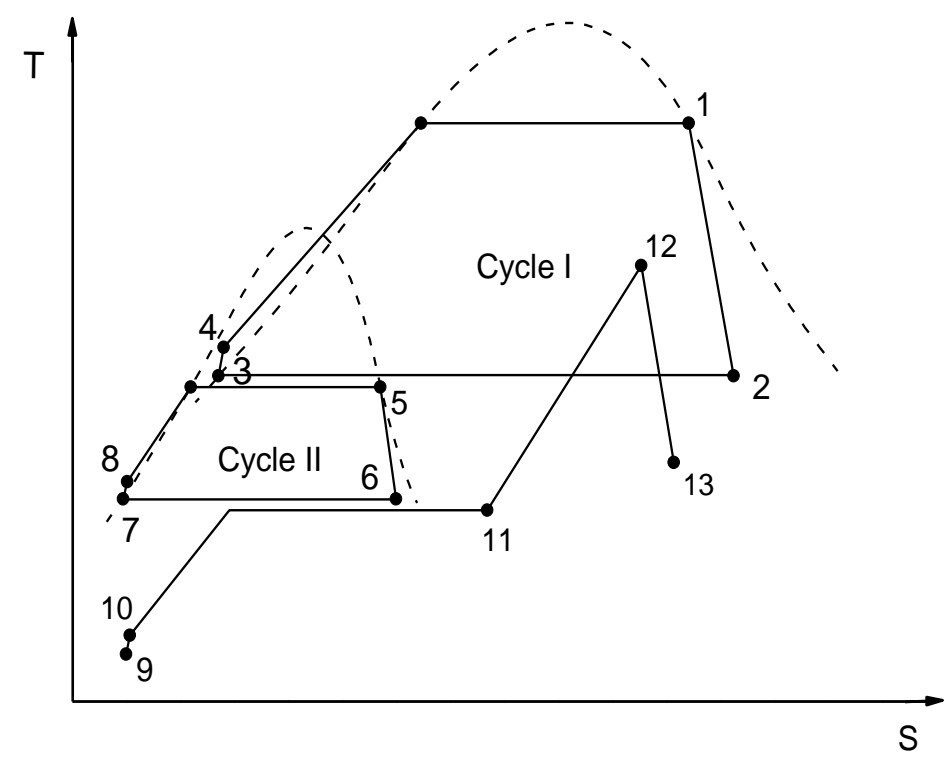

Fig. 2. $\mathrm{T}-\mathrm{s}$ diagram with the state points as defined in Fig. 1. 


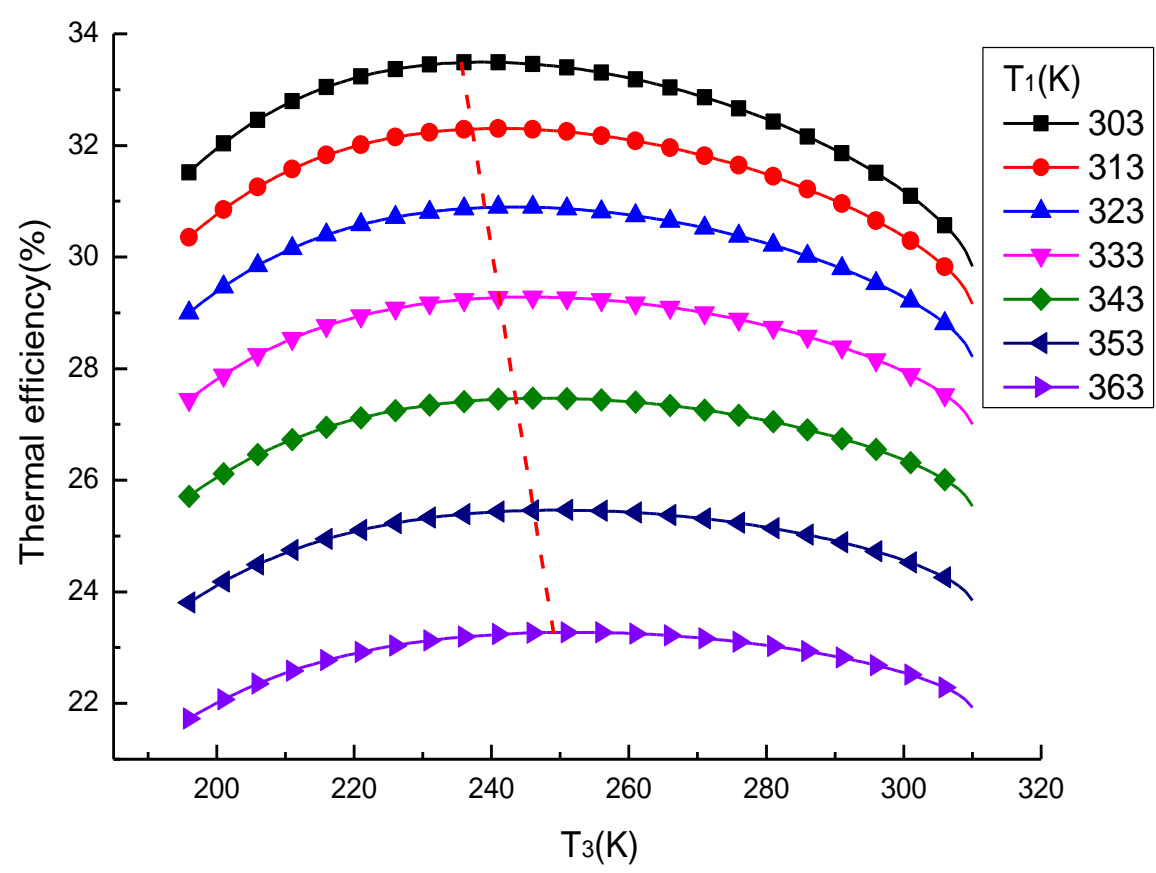

Fig. 3. Thermal efficiency varying with $\mathrm{T}_{1}$ and $\mathrm{T}_{3}$.

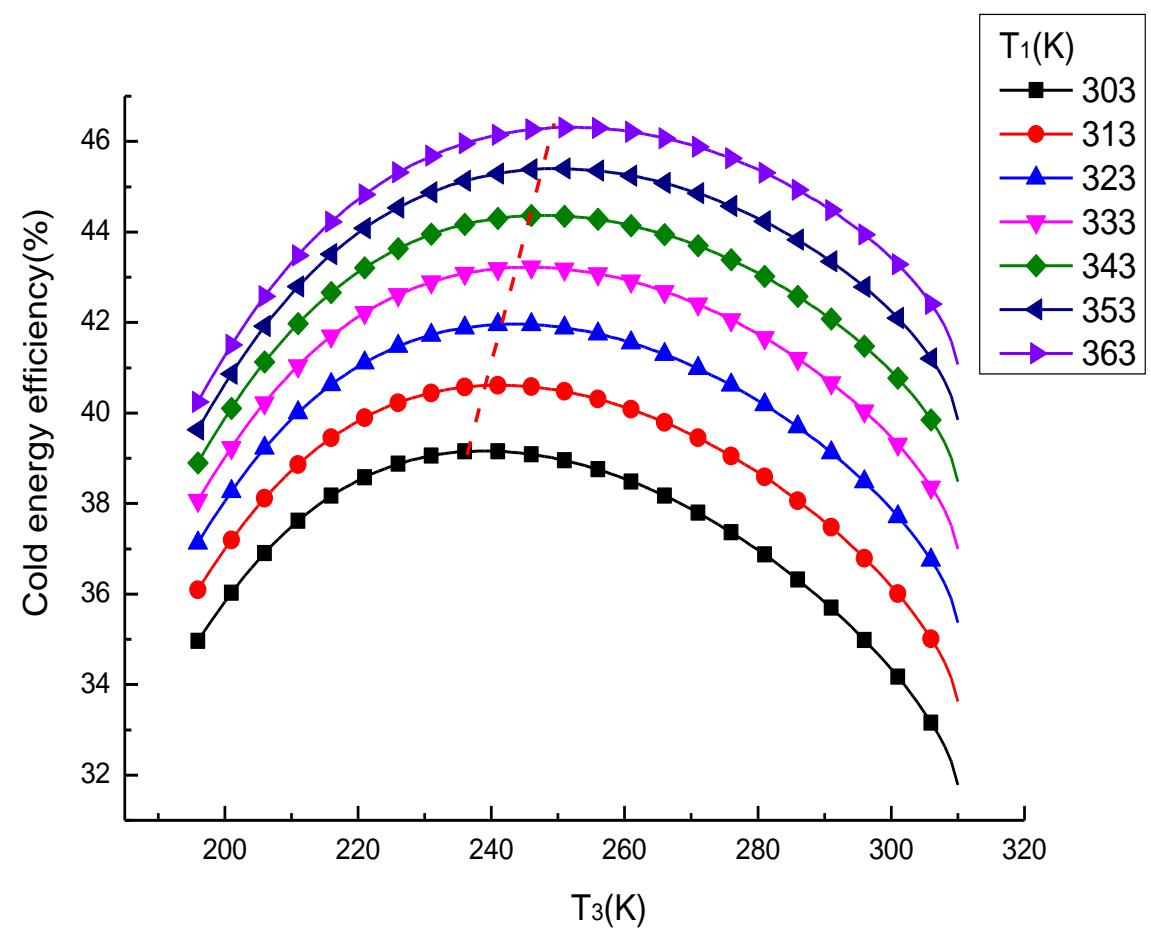

Fig. 4. Cold energy efficiency varying with $\mathrm{T}_{1}$ and $\mathrm{T}_{3}$. 


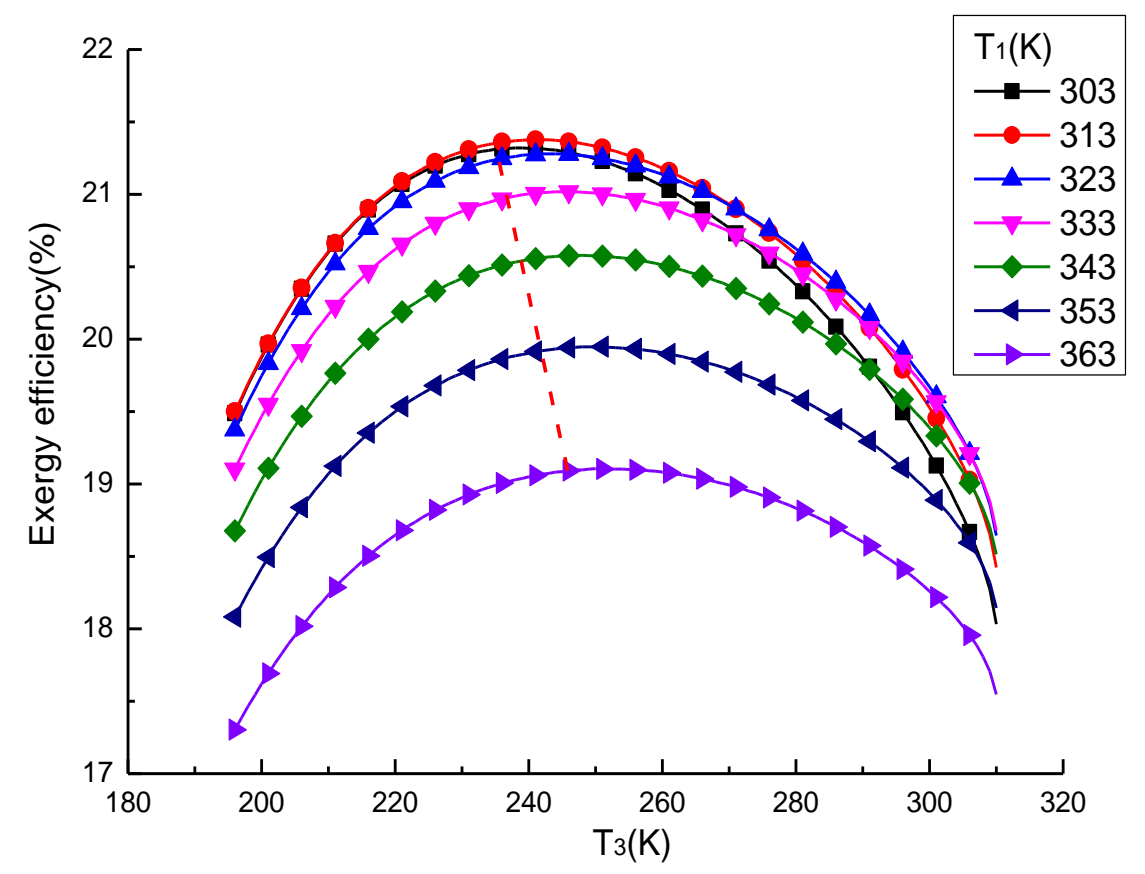

Fig. 5. Exergetic efficiency varying with $\mathrm{T}_{1}$ and $\mathrm{T}_{3}$.

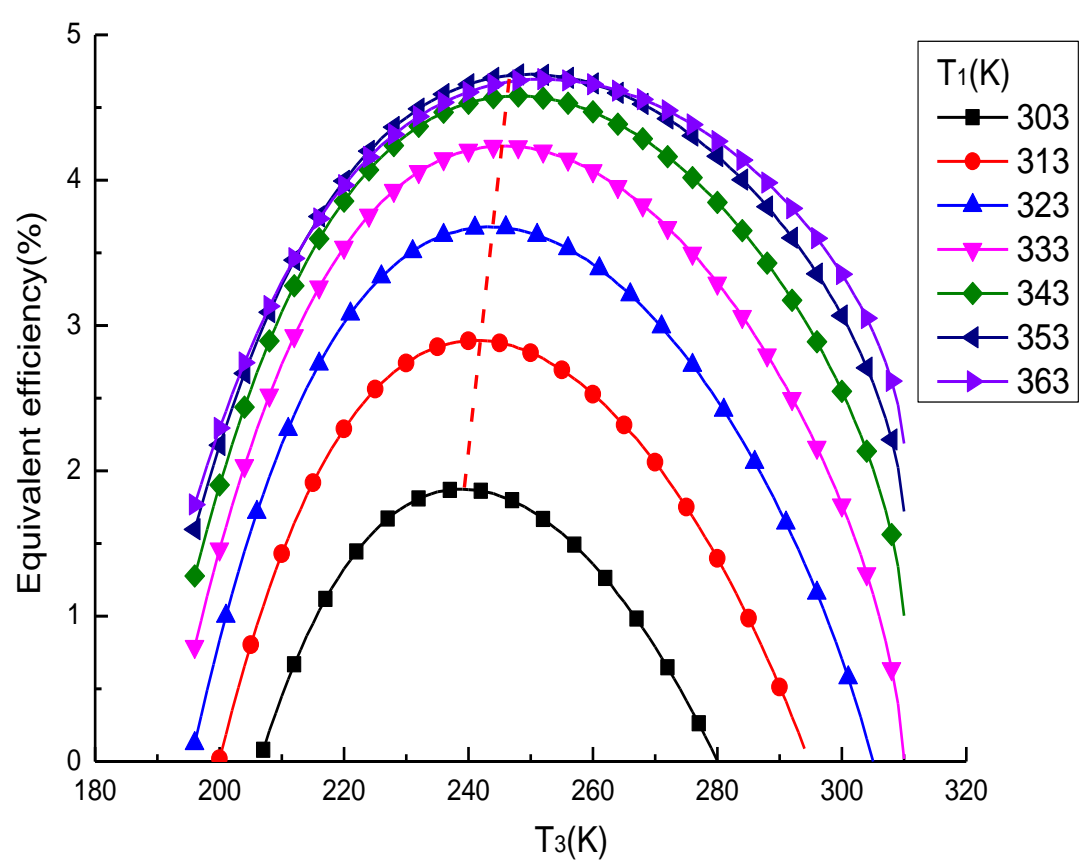

Fig. 6. Equivalent efficiency varying with $\mathrm{T}_{1}$ and $\mathrm{T}_{3}$. 


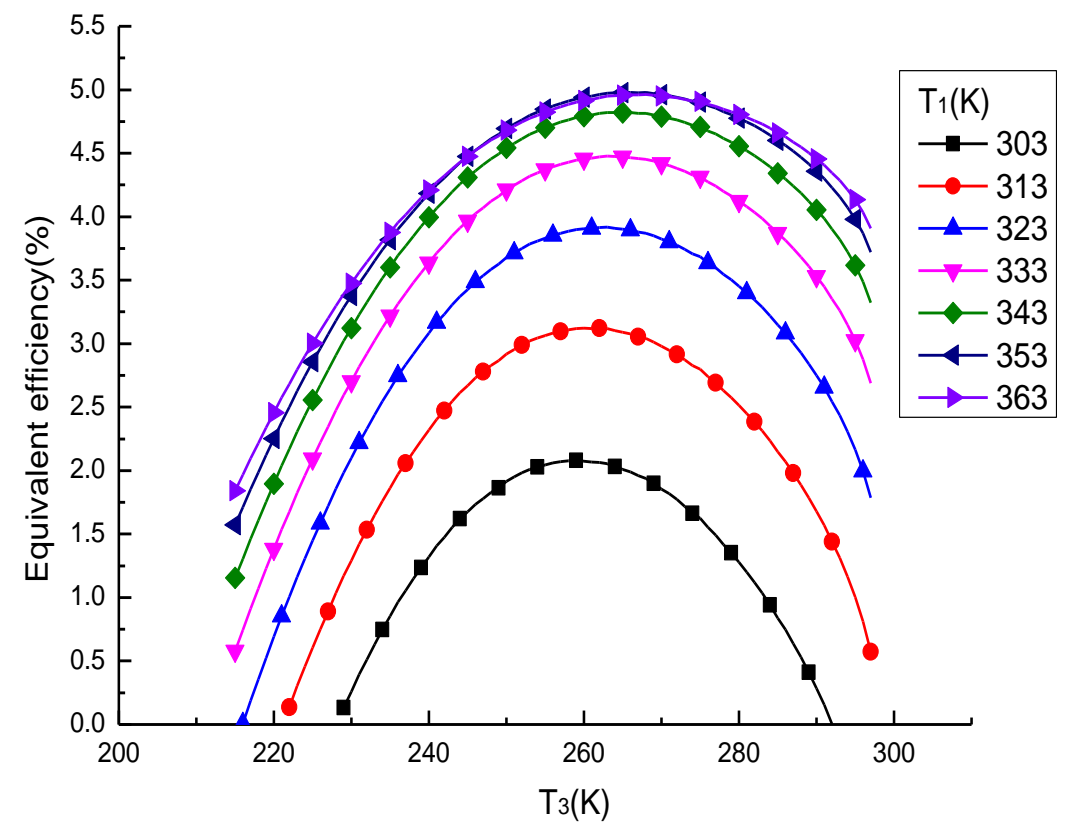

Fig. 7. Equivalent efficiency varying with $\mathrm{T}_{1}$ and $\mathrm{T}_{3}$ on the use of isopentane/R116.

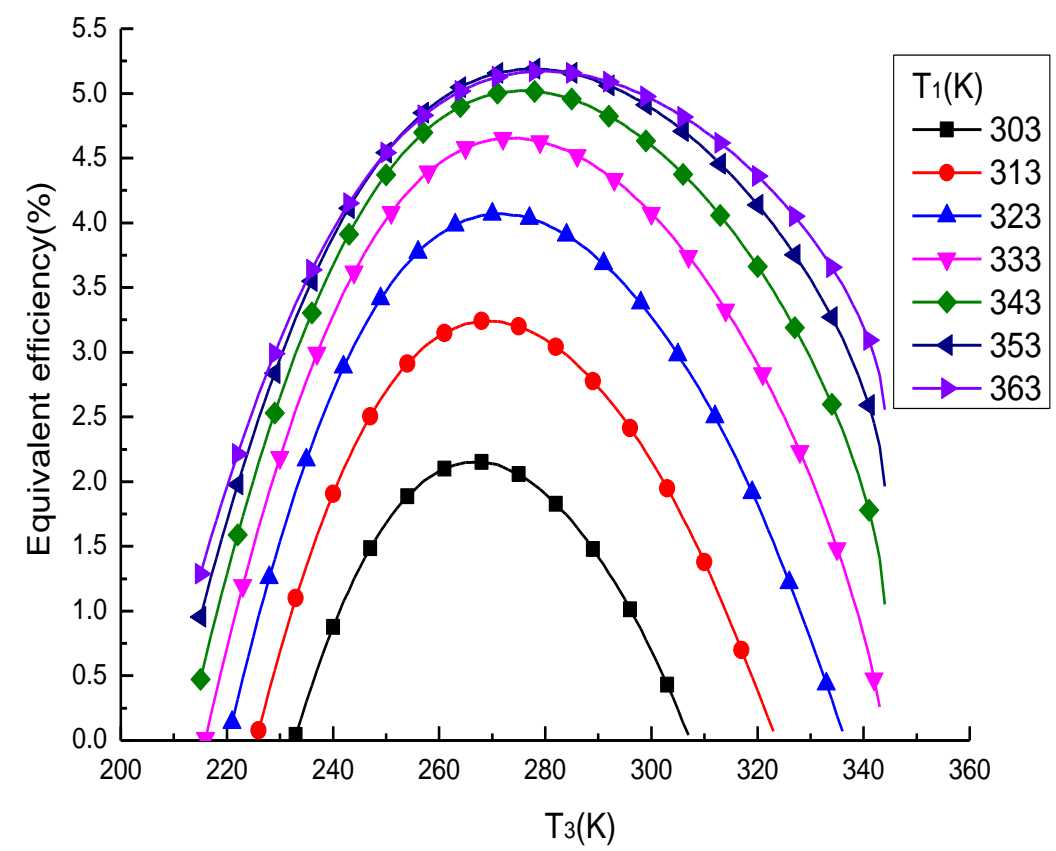

Fig. 8. Equivalent efficiency varying with $\mathrm{T}_{1}$ and $\mathrm{T}_{3}$ on the use of isopentane/R125. 


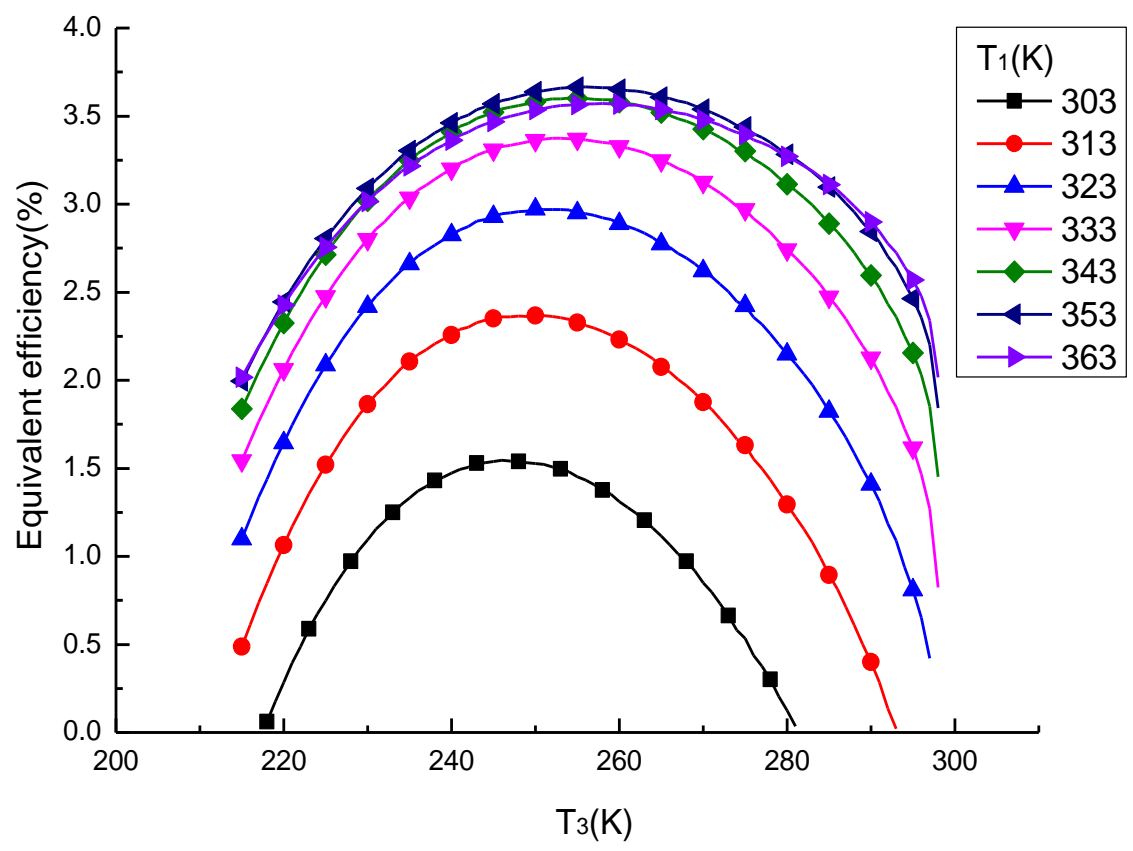

Fig. 9. Equivalent efficiency varying with $\mathrm{T}_{1}$ and $\mathrm{T}_{3}$ on the use of R227ea/R116.

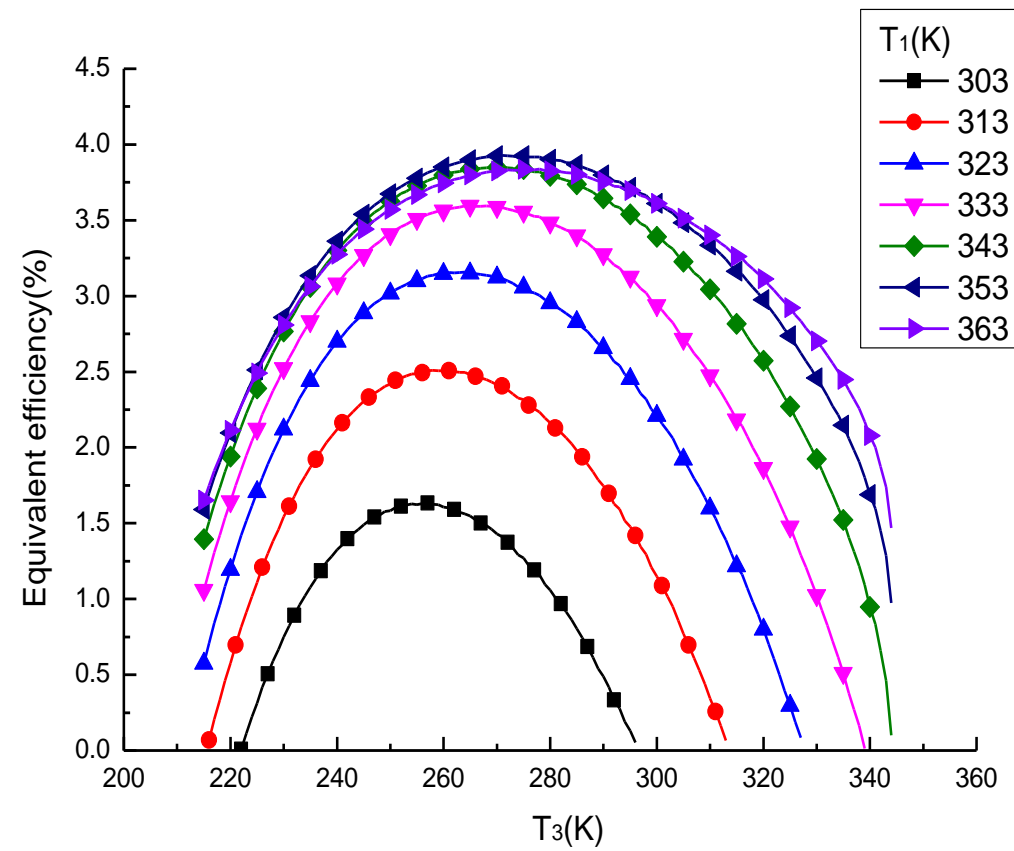

Fig. 10. Equivalent efficiency varying with $\mathrm{T}_{1}$ and $\mathrm{T}_{3}$ on the use of $\mathrm{R} 227 \mathrm{ea} / \mathrm{R} 125$. 


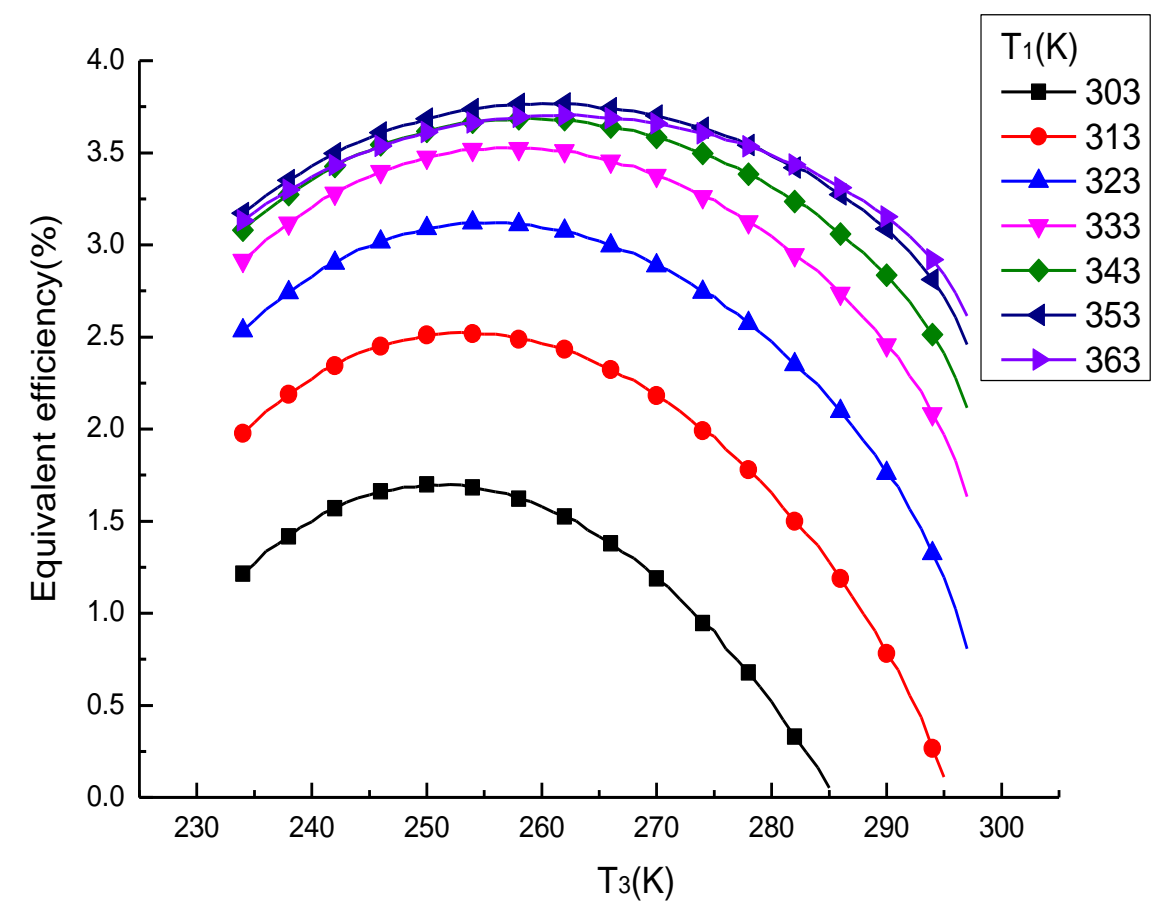

Fig. 11. Equivalent efficiency varying with $\mathrm{T}_{1}$ and $\mathrm{T}_{3}$ on the use of RC318/R116.

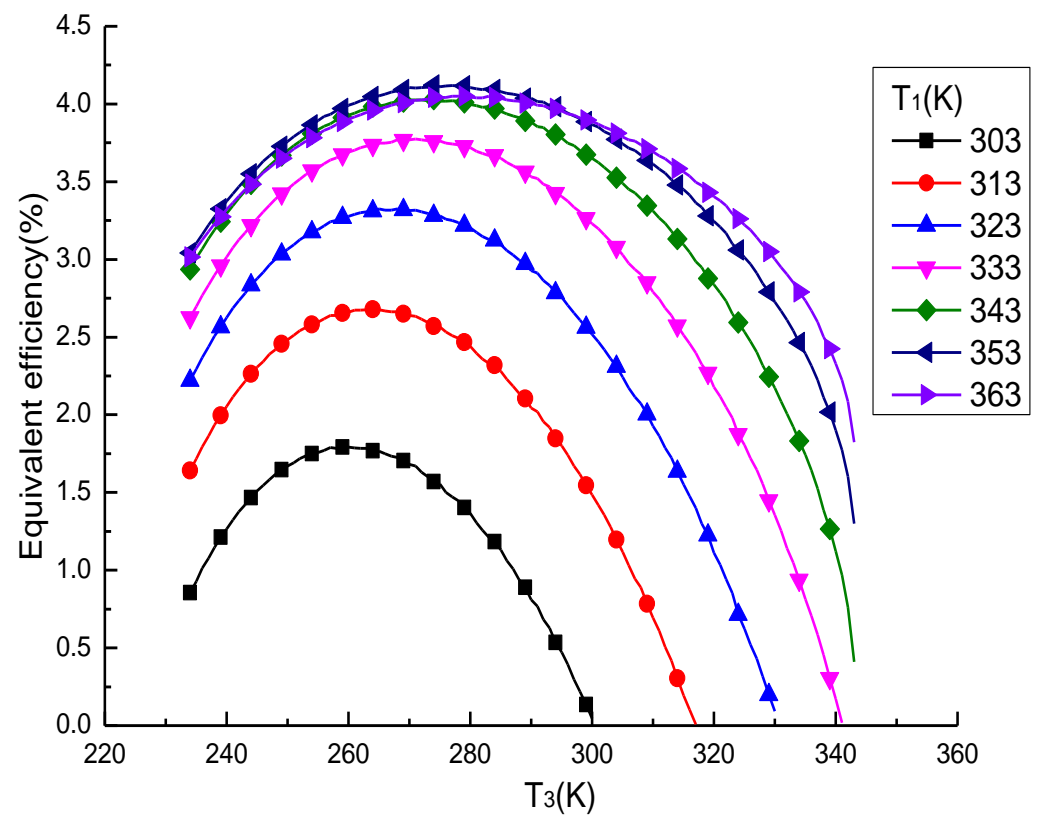

Fig. 12. Equivalent efficiency varying with $T_{1}$ and $T_{3}$ on the use of RC318/R125. 


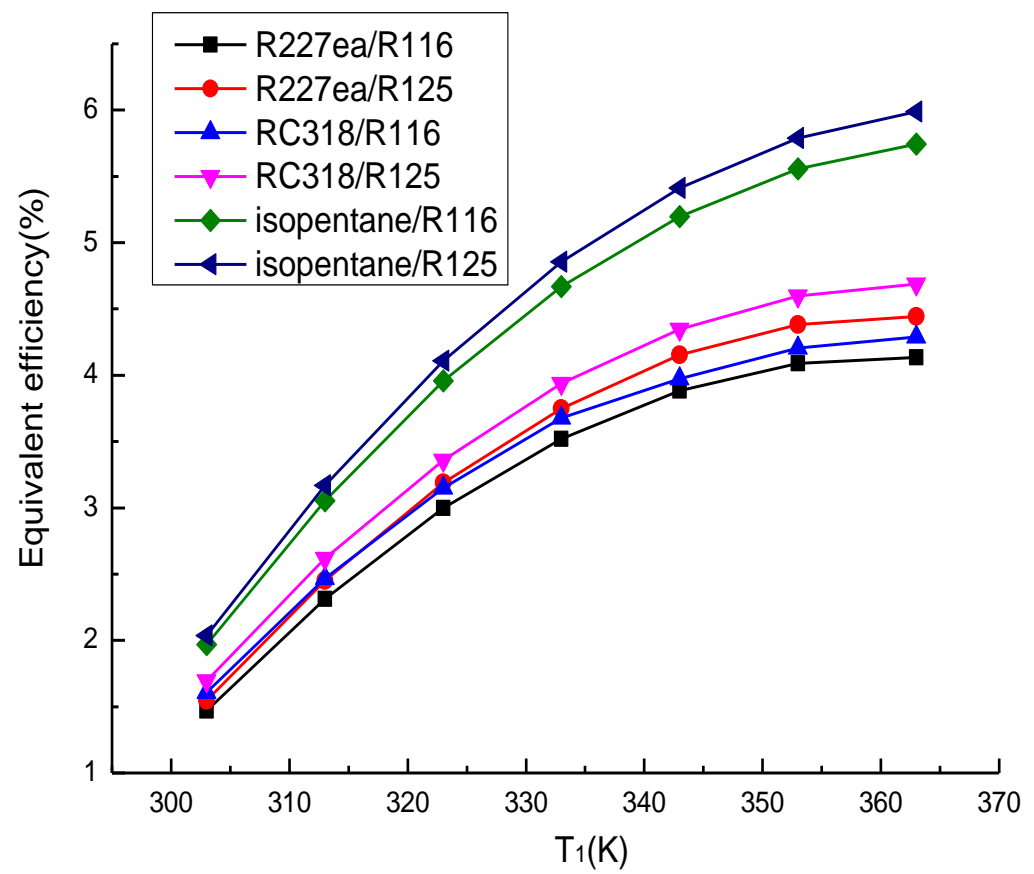

Fig. 13. Peak equivalent efficiency at each $\mathrm{T}_{1}$ on the use of ETC.

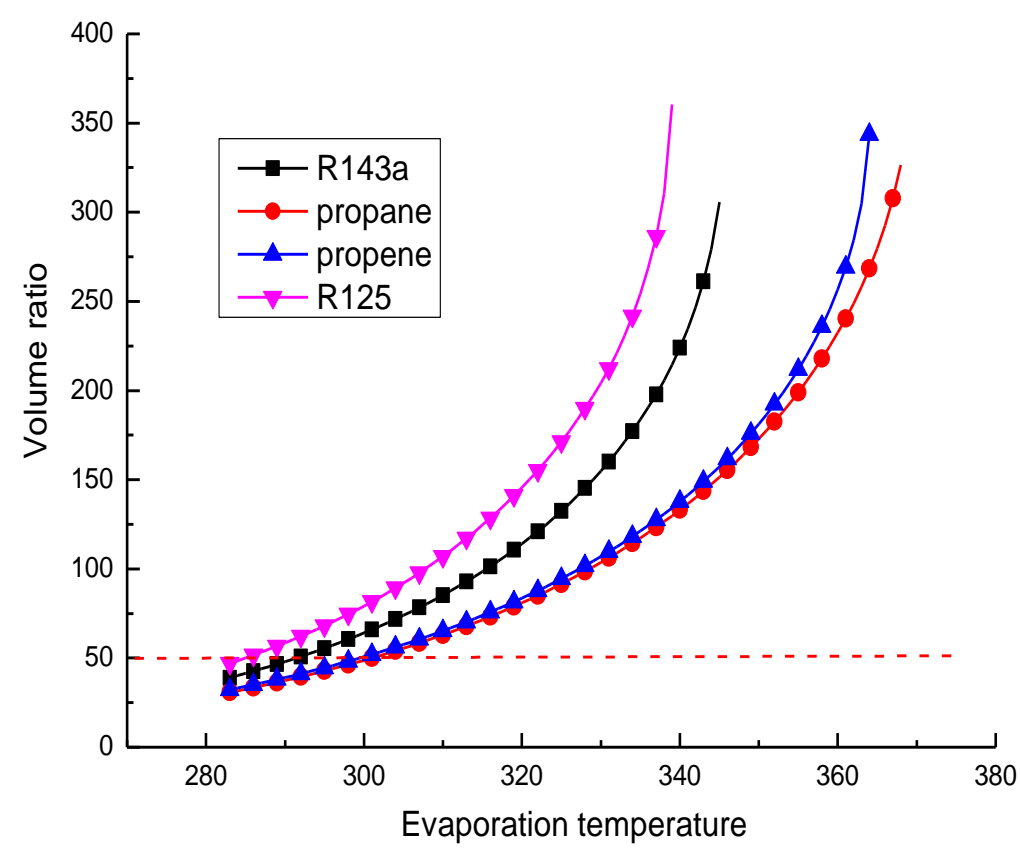

Fig. 14. VR of the single-stage ORC varying with evaporation temperature. 
Table 1. Fixed parameters for calculation.

\begin{tabular}{ll}
\hline Term & Value \\
\hline Ambient temperature, $T_{0}$ & $298 \mathrm{~K}$ \\
Evaporation pressure for LNG & $3 \mathrm{MPa}$ \\
Pressure for NG entering into urban pipeline network & $0.4 \mathrm{MPa}$ \\
Mass flow rate of LNG, $m_{L N G}$ & $1 \mathrm{~kg} / \mathrm{s}$ \\
Solar radiation intensity, $G$ & $1 \mathrm{~kW} / \mathrm{m}^{2}$ \\
Pinch-point temperature difference & $5 \mathrm{~K}$ \\
Organic fluid pump isentropic efficiency, $\eta_{P}$ & 0.8 \\
Water pump efficiency, $\varepsilon_{p}$ & 0.75 \\
Water pump hydraulic head, $H$ & $10 \mathrm{~m}$ \\
Expander isentropic efficiency, $\eta_{E}$ & 0.75 \\
Senerator efficiency, $\varepsilon_{g}$ & 0.95 \\
\hline
\end{tabular}


Table 2. Parameters of each state point for LNG.

\begin{tabular}{llllll}
\hline State & $\mathrm{T}(\mathrm{K})$ & $\mathrm{P}(\mathrm{MPa})$ & $\mathrm{h}(\mathrm{kJ} / \mathrm{kg})$ & $\mathrm{s}(\mathrm{kJ} / \mathrm{kg} \cdot \mathrm{K})$ & Quality \\
\hline 9 & 111.51 & 0.1 & -0.558 & -0.005 & 0.000 \\
10 & 112.76 & 3.0 & 8.002 & 0.010 & 0.000 \\
11 & 177.27 & 2.99 & 539.93 & 3.338 & 1.000 \\
12 & 288.18 & 2.98 & 857.2 & 4.769 & superheated \\
13 & 198.62 & 0.4 & 689.76 & 5.07 & superheated \\
\hline
\end{tabular}

Table 3. Thermodynamic properties of the working fluids.

\begin{tabular}{ccccccc}
\hline Working & Relative & Boiling & Triple-point & Critical & Ozone & Global \\
fluid & molecular & point & temperature & temperature & depletion & warming \\
& mass & $(\mathrm{K})$ & $(\mathrm{K})$ & $(\mathrm{K})$ & potential & potential \\
\hline Ammonia & 17 & 239.82 & 195.5 & 405.4 & 0 & $<1$ \\
Isopentane & 72 & 300.98 & 112.65 & 460.35 & 0 & 0 \\
R227ea & 170 & 256.81 & 146.35 & 374.9 & 0 & 2050 \\
RC318 & 200 & 267.18 & 233.35 & 388.38 & 0 & 10250 \\
Ethane & 30 & 184.55 & 90.35 & 305.33 & 0 & 20 \\
R116 & 138 & 195.06 & 173.1 & 293.03 & 0 & 11900 \\
R125 & 120 & 225.06 & 172.52 & 339.17 & 0 & 2800 \\
\hline
\end{tabular}


Table 4. Maxima of various efficiencies and corresponding state points for ammonia and ethane.

\begin{tabular}{llllllll}
\hline Various efficiencies & Maximum & $\mathrm{T}_{1}(\mathrm{~K}) /$ & $\mathrm{T}_{2}(\mathrm{~K}) /$ & $\mathrm{T}_{3}(\mathrm{~K}) /$ & $\mathrm{T}_{4}(\mathrm{~K}) /$ & $\mathrm{T}_{5}(\mathrm{~K}) /$ & $\mathrm{T}_{8}(\mathrm{~K}) /$ \\
& $(\%)$ & $\mathrm{P}_{1}(\mathrm{MPa})$ & $\mathrm{P}_{2}(\mathrm{MPa})$ & $\mathrm{P}_{3}(\mathrm{MPa})$ & $\mathrm{P}_{4}(\mathrm{MPa})$ & $\mathrm{P}_{5}(\mathrm{MPa})$ & $\mathrm{P}_{8}(\mathrm{MPa})$ \\
\hline Thermal efficiency & 33.49 & $303 / 1.16$ & $239 / 0.11$ & $239 / 0.10$ & $240 / 1.17$ & $234 / 0.80$ & $183 / 0.81$ \\
Cold energy efficiency & 46.31 & $363 / 5.10$ & $252 / 0.19$ & $252 / 0.18$ & $253 / 5.11$ & $247 / 1.19$ & $183 / 1.20$ \\
Exergetic efficiency & 21.38 & $313 / 1.55$ & $241 / 0.12$ & $241 / 0.11$ & $242 / 1.56$ & $236 / 0.85$ & $183 / 0.86$ \\
Equivalent efficiency & 4.74 & $356 / 4.40$ & $249 / 0.17$ & $249 / 0.16$ & $250 / 4.41$ & $244 / 1.09$ & $183 / 1.10$ \\
\hline
\end{tabular}

Table 5. Maximum equivalent efficiencies for different fluids on the use of FPC.

\begin{tabular}{cccccccc}
\hline Working fluids & Maxima & $\mathrm{T}_{1}(\mathrm{~K}) /$ & $\mathrm{T}_{2}(\mathrm{~K}) /$ & $\mathrm{T}_{3}(\mathrm{~K}) /$ & $\mathrm{T}_{5}(\mathrm{~K}) /$ & $\mathrm{T}_{6}(\mathrm{~K}) /$ & VRs for \\
& & $\mathrm{P}_{1}(\mathrm{MPa})$ & $\mathrm{P}_{2}(\mathrm{MPa})$ & $\mathrm{P}_{3}(\mathrm{MPa})$ & $\mathrm{P}_{5}(\mathrm{MPa})$ & $\mathrm{P}_{6}(\mathrm{MPa})$ & $\mathrm{E} 1 / \mathrm{E} 2$ \\
\hline R227ea/R116 & $3.66 \%$ & $353 / 1.85$ & $291 / 0.11$ & $256 / 0.10$ & $251 / 0.98$ & $196 / 0.06$ & $22.4 / 16.6$ \\
R227ea/R125 & $3.93 \%$ & $353 / 1.85$ & $300 / 0.19$ & $271 / 0.18$ & $266 / 0.53$ & $198 / 0.02$ & $12.8 / 27.0$ \\
RC318/R116 & $3.77 \%$ & $353 / 1.34$ & $306 / 0.09$ & $261 / 0.08$ & $256 / 1.11$ & $197 / 0.06$ & $18.4 / 19.7$ \\
RC318/R125 & $4.15 \%$ & $354 / 1.37$ & $313 / 0.15$ & $275 / 0.14$ & $270 / 0.61$ & $199 / 0.02$ & $11.3 / 30.9$ \\
Isopentane/R116 & $4.99 \%$ & $357 / 0.50$ & $329 / 0.04$ & $266 / 0.03$ & $261 / 1.32$ & $214 / 0.06$ & $14.1 / 23.3$ \\
Isopentane/R125 & $5.20 \%$ & $357 / 0.50$ & $315 / 0.05$ & $277 / 0.04$ & $272 / 0.65$ & $284 / 0.02$ & $9.9 / 33.0$ \\
\hline
\end{tabular}


Table 6. Maximum equivalent efficiencies for different fluids on the use of ETC.

\begin{tabular}{|c|c|c|c|c|c|c|c|}
\hline Working fluids & Maxima & $\mathrm{T}_{1}(\mathrm{~K}) /$ & $\mathrm{T}_{2}(\mathrm{~K}) /$ & $\mathrm{T}_{3}(\mathrm{~K}) /$ & $\mathrm{T}_{5}(\mathrm{~K}) /$ & $\mathrm{T}_{6}(\mathrm{~K}) /$ & VRs for \\
\hline & & $\mathrm{P}_{1}(\mathrm{MPa})$ & $\mathrm{P}_{2}(\mathrm{MPa})$ & $\mathrm{P}_{3}(\mathrm{MPa})$ & $\mathrm{P}_{5}(\mathrm{MPa})$ & $\mathrm{P}_{6}(\mathrm{MPa})$ & E1/E2 \\
\hline R227ea/R116 & $4.14 \%$ & $360 / 2.15$ & $292 / 0.11$ & $256 / 0.10$ & $251 / 0.98$ & 196/0.06 & $28.0 / 16.6$ \\
\hline R227ea/R125 & $4.45 \%$ & $362 / 2.24$ & $302 / 0.22$ & $275 / 0.21$ & $270 / 0.61$ & 199/0.02 & $14.9 / 30.9$ \\
\hline RC318/R116 & $4.29 \%$ & $363 / 1.66$ & $310 / 0.09$ & $263 / 0.08$ & $258 / 1.18$ & 197/0.06 & $21.9 / 21.8$ \\
\hline $\mathrm{RC} 318 / \mathrm{R} 125$ & $4.69 \%$ & $363 / 1.66$ & $318 / 0.18$ & $280 / 0.17$ & $275 / 0.17$ & $200 / 0.02$ & $12.3 / 36.4$ \\
\hline Isopentane/R116 & $5.74 \%$ & $363 / 0.58$ & $313 / 0.04$ & $268 / 0.03$ & $263 / 1.40$ & 198/0.06 & $15.3 / 24.9$ \\
\hline Isopentane/R125 & $5.99 \%$ & $363 / 0.58$ & $319 / 0.06$ & $280 / 0.05$ & $275 / 0.71$ & $200 / 0.02$ & $10.4 / 36.4$ \\
\hline
\end{tabular}




\section{Nomenclature}

\begin{tabular}{|c|c|c|c|}
\hline$A$ & aperture area, $\mathrm{m}^{2}$ & $g$ & generator \\
\hline$C$ & heat capacity, $\mathrm{kJ} / \mathrm{kg} \cdot \mathrm{K}$ & in & inlet \\
\hline$E$ & exergy, kW & $m$ & mean \\
\hline$G$ & solar radiation intensity, $\mathrm{kW} / \mathrm{m}^{2}$ & $\max$ & maximum \\
\hline$h$ & enthalpy, $\mathrm{kJ} / \mathrm{kg}$ & net & net \\
\hline$H$ & hydraulic head, m & out & outlet \\
\hline$m$ & mass flow rate, $\mathrm{kg} / \mathrm{s}$ & $s$ & isentropic \\
\hline$S$ & entropy, $\mathrm{kJ} / \mathrm{kg} \cdot \mathrm{K}$ & $S$ & solar \\
\hline$T$ & temperature, $\mathrm{K}$ & $T$ & thermal \\
\hline$v$ & specific volume, $\mathrm{m}^{3} / \mathrm{kg}$ & $w$ & water \\
\hline$W$ & power output, $\mathrm{kW}$ & \multicolumn{2}{|c|}{ Abbreviation } \\
\hline$\eta$ & efficiency & $\mathrm{CPP}$ & cost per net power output \\
\hline$\varepsilon$ & mechanic efficiency & $\mathrm{E}$ & expander \\
\hline \multicolumn{2}{|c|}{ Subscripts } & ETC & evacuated tube collectors \\
\hline $\mathrm{I}, \mathrm{II}$ & cycle I, II & $\mathrm{FPC}$ & flat plate collectors \\
\hline $1-15$ & state points & $\mathrm{HX}$ & heat exchanger \\
\hline 0 & ambient state & $\mathrm{NG}$ & natural gas \\
\hline$C$ & cold energy & ORC & organic Rankine cycle \\
\hline$e q$ & equivalent & $\mathrm{P}$ & pump \\
\hline$e x$ & exergetic & VR & volume ratio \\
\hline
\end{tabular}

